\title{
Frontières
}

\section{Quelques réflexions de... Jovette Marchessault}

\section{Jovette Marchessault}

Volume 12, numéro 1, automne 1999

Suicides, générations et culture

URI : https://id.erudit.org/iderudit/1075917ar

DOI : https://doi.org/10.7202/1075917ar

Aller au sommaire du numéro

Éditeur(s)

Université du Québec à Montréal

ISSN

1180-3479 (imprimé)

1916-0976 (numérique)

Découvrir la revue

Citer ce document

Marchessault, J. (1999). Quelques réflexions de... Jovette Marchessault.

Frontières, 12(1), 27-27. https://doi.org/10.7202/1075917ar d'utilisation que vous pouvez consulter en ligne.

https://apropos.erudit.org/fr/usagers/politique-dutilisation/ 


\section{Quelques réflexions de... Jovette Marchessault}

Qu'allons-nous faire? Et si nos enfants se suicidaient parce que nous avons commis le vol le plus terrible qui soit, celui de leur avoir enlevé l'espérance du futur. Ils sont des riens à qui on ne dit plus rien. Quand nous leur parlons nous ne savons pas toujours éviter les mots qui tuent. C'est le silence qui tue, dit-on, mais notre parole est d'une telle violence que finalement elle est un silence.

"Quand je serai grand... Quand je serai grande, je ferai...». Nous avons tous prononcé cette phrase magique de l'enfance où se dissimule l'extraordinaire présence d'un temps futur car nous voulions continuer de vivre au coeur d'une vie tournée vers l'avant. À l'époque - j'ai soixante ans - il y avait encore quelque chose pour nourrir les exigences intérieures que chaque enfant porte en elle, en lui. Aujourd'hui, la peur et le désespoir se sont installés... Je pense à ces pères qui ne croyant plus que demain est dans la suite des jours décident, avant de se suicider, de détruire leurs enfants comme si c'était là une gangrène issue d'eux-mêmes. Dans nos sociétés, l'intelligentsia radote sur le déficit financier alors que le seul vrai déficit est d'ordre éthique et spirituel. Mettant leur misérable carcasse au-dessus de tout, de plus en plus de gens approuvent le suicide. On aime bien ces artistes qui se tuent avec des gestes antiques, sur les tréteaux sanglants de l'histoire humaine. Au Québec, le suicide est une option parmi les autres! Mais à mes yeux, rien ne peut légitimer le suicide qui demeure simplement identique à l'homicide avec préméditation, bref au meurtre.

Je ne refuse pas les belles lumières des sciences humaines mais je crois qu'elles ne suffisent pas à tout. Au coeur du décalogue, il y a cette injonction de vie: «Tu ne tueras point». J'entends aussi: tu ne tueras pas ce que tu es. C'est heureux, nous ne supportons plus les tutelles religieuses, mais nous tendons à les remplacer par cette chose mutilante qui fonctionne uniquement selon le principe de raison et la logique technologique, tuant chez nos enfants la quête d'infini, de justice et de bonté. De beauté! Nos enfants pleurent, nos hommes pleurent, eux qui la subissent avec une acuité incommensurable. Qu'allons-nous faire? Continuer de les peser, de les évaluer comme des marchandises qu'on achète à notre convenance. Impossible car nous avons déjà accumulé un stock ruineux d'âmes d'enfants usagées dont personne ne veut et qui encombrent le «système éducatif». Il faudra solder à perte, déficit économique envisagé... Il y en a plein qui sont à vendre, de ces âmes usagées, seulement les unes sont trop demandées et les autres inutilement offertes. La loi du marché, offre et demande, est une très mauvaise balance. Qu'allons-nous faire?

Je suis dramaturge, membre de la société humaine en des temps où presque tout ce qui s'écrit se rédige dans les officines du désespoir: pendaison, mutilation, viol et humiliation des vivants et des vivantes, voici les causes et leurs effets et tant pis si le goût de mourir vous submerge, nous disent ces artistes... C'est comme si le dynamomètre de leur esprit ne fonctionnait qu'à la dénonciation. Qu'allons-nous faire?

Les belles routes de la terre nous attendent, toutes générations confondues, pour y vivre et y mourir un jour, certes, mais pas avant l'actualisation des possibilités uniques de chacun, pas avant l'accomplissement de ce futur fragile et périssable, le nôtre, celui de la planète. Que pouvons-nous faire? Et si nous commencions par apprendre à parler à autrui pour qu'il vive. 